\title{
A novel rhamnolipid-producing Pseudomonas aeruginosa ZS1 isolate derived from petroleum sludge suitable for bioremediation
}

\author{
Tao Cheng ${ }^{1 \dagger}$, Jibei Liang ${ }^{1 \dagger}$, Jing $\mathrm{He}^{2}$, Xingcui Hu${ }^{1}$, Zhiwei $\mathrm{Ge}^{3}$ and Jianhua Liu ${ }^{1,2^{*}}$ (D)
}

\begin{abstract}
Petroleum pollutants emulsified by biosurfactants facilitate uptake and biodegradation by environmental microbes. In this report, we show the characterization of an indigenous surfactant-producing crude-oil-eating microbe isolated from petroleum-sludge in Zhoushan islands, China, where one of the national strategic petroleum reservoirs is located. We examined biosurfactant activities using surface tension analysis on mixed culture originated from oil-sludge microbes. In parallel, dynamics of individual microbial populations in cultures were monitored using the terminal fluorescence labeled (TFL)-RFLP method. Biosurfactant activity was found to be associated with a dominant microbial species designated as ZS1 (Zhou-Shan isolate 1). Cell-free supernatant from the ZS1 culture exhibited 100\% emulsification index against crude oil and reduces surface tension to $26.5 \mathrm{mN} / \mathrm{m}$. Sequence-based analysis suggested that the ZS1 belongs to the group of Pseudomonas aeruginosa. LC-MS/MS analysis indicated that the rhamnolipids produced by the ZS1 consisted of 7 monorhamnolipid and 11 dirhamnolipid homologues (RL7-11), two of which were novel. Maximum yield of rhamnolipids in shake-flask ZS1 culture could reach $44 \mathrm{~g} / \mathrm{l}$. Furthermore, we showed that ZS1 was capable of growing in MS medium supplemented with 1\% crude oil as sole carbon source, in which cell mass increase coincided with the formation of crude-oil emulsion. Half of the crude oil was consumed by the ZS1 in 12 days. Taken together, our results show that ZS1 produces high level of rhamnolipids that effectively emulsify crude oil accelerating its uptake and degradation. Hence, it is suitable for bioremediation of petroleum pollutants in Zhoushan coastal areas.
\end{abstract}

Keywords: Bioremediation, Biosurfactant, Emulsification, Oil sludge, Rhamnolipids, Pseudomonas aeruginosa

\section{Introduction}

Petroleum leaks and spills are often linked to accidents resulting from activities related to the petrochemical industry involving oil drilling rigs, transportation tankers and pipelines, and storage reservoirs (Holliger et al. 1997). It has been estimated that at least 400,000 metric tons of natural crude oil leaked to the environment

\footnotetext{
*Correspondence: liujh2013@zju.edu.cn

TTao Cheng and Jibei Liang contributed equally to this work

${ }^{1}$ Marine Biology, Ocean College, Zhejiang University, 1 Zheda Road, Dinghai District, Zhoushan Campus, Marine Science Building, Room 379, Zhoushan 316000, Zhejiang, China

Full list of author information is available at the end of the article
}

every year worldwide (Kvenvolden and Cooper 2003). Chemically synthesized surfactants are routinely used for removal of petroleum pollutants (Kanaly and Harayama 2010). However, most chemically synthesized surfactants are only partially and slowly biodegraded by the environmental microbes, some of which are known to be toxic to animals, ecosystems, and humans, contributing to secondary pollutants (Henkel et al. 2012; Murphy et al. 2005).

Biosurfactants are surface-active amphiphilic compounds produced by living cells and provide a promising alterative to chemically synthesized surfactants, since they are low toxicity, high biodegradability, and 
ecological safety (Sponza and Gök 2010). A number of microorganisms have shown to produce biosurfactants, for example, Acinetobacter calcoaceticus, Bacillus subtilis, Pseudomonas aeruginosa, and Starmerella bombicola produce emulsan, surfactin, rhamnolipids, and sophorolipids, respectively (Cooper et al. 1981; Shoham et al. 1983; Sponza and Gök 2010; Zajic and Supplison 1972). Rhamnolipids are among the most effective surfactants in removing crude petroleum oil from contaminated sites (Desai and Banat 1997; Lang and Wullbrandt 1999; Santa Anna et al. 2002; Soberón-Chávez et al. 2005).

Rhamnolipids are glycolipids whose amphiphilic structure consists of one or two L-rhamnose moieties (rha) linked in a 1,2-glycosidic linkage to up to three $\beta$-hydroxy fatty acids with chain lengths ranging from eight to sixteen (Abdel-Mawgoud et al. 2010; Edward and Hayashi 1965). The most abundant species of rhamnolipids produced by $P$. aeruginosa are monorhamnolipids $\alpha$-L-rhamnopyranosyl$\beta$-hydroxydecanoyl- $\beta$-hydroxydecanoate $\quad\left(\right.$ rha- $\mathrm{C}_{10}-\mathrm{C}_{10}$ ) and $\alpha$-L-rhamnopyranosyl- $\beta$-hydroxydecanoate (rha- $\mathrm{C}_{10}$ ) and dirhamnolipids $\alpha$-L-rhamnopyranosyl- $\alpha$-L-rhamnopyranosyl- $\beta$-hydroxydecanoyl- $\beta$-hydroxydecanoate(rha-rha$\left.\mathrm{C}_{10}-\mathrm{C}_{10}\right)$ and $\alpha$-L-rhamnopyranosyl- $\alpha$-L-rhamnopyranosyl- $\beta$-hydroxydecanoate (rha-rha- $\mathrm{C}_{10}$ ) (Abdel-Mawgoud et al. 2010).

Extra rhamnose ring in dirhamnolipids (e.g., rha-rha$\mathrm{C}_{10}-\mathrm{C}_{10}$ ) confers high hydrophilicity compared to monorhamnolipids (e.g., rha- $C_{10}-C_{10}$ ). On the other hand, extra fatty acid chain in dilipidic rhamnolipids (e.g., rha-rha$\mathrm{C}_{10}-\mathrm{C}_{10}$ ) exhibits high hydrophobicity compared to monolipidic rhamnolipids (e.g., rha-rha- $\mathrm{C}_{10}$ ). These properties affect the rhamnolipid's amphiphilicity that determines their stability in aqueous phase, capability to solubilize hydrophobic organic compounds, and bioavailability (Mata-Sandoval et al. 1999). Monolipidic rhamnolipids such as rha- $\mathrm{C}_{10}$ and rha-rha- $\mathrm{C}_{10}$ displayed high critical micelle concentrations (CMC) values up to $200 \mathrm{mg} / \mathrm{l}$, whereas dirhamnolipids like rha-rha- $\mathrm{C}_{10}-\mathrm{C}_{10}$ and monorhamnolipid rha- $\mathrm{C}_{10}-\mathrm{C}_{10}$ show relatively low $\mathrm{CMC}$ values from 40 to $120 \mathrm{mg} / \mathrm{l}$ (Abdel-Mawgoud et al. 2009; Haba et al. 2003). Because of a wide range of amphiphilicities, whole mixture of rhamnolipid congeners produced by $P$. aeruginosa can serve as good surface-active agents in some industrial applications in a cost-effective manner (Abalos et al. 2001; Deziel et al. 1999; Ma et al. 2016).

Rhamnolipid biosynthesis is believed to be catalyzed by the rhamnosyltransferase 1 chain A (RhlA) and chain $B(\mathrm{RhlB})$ and rhamnosyltransferase 2 (RhlC). RhlA catalyzes the formation of $\beta$-hydroxyalkanoyl- $\beta$ hydroxyalkanoic acid (HAA) from $\beta$-hydroxyacyl-APC or $\beta$-hydroxyacyl-CoA (Rehm et al. 1998). RhlB catalyzes the formation of monorhamnolipid from HAA and
dTDP-L-rhamnose (Ochsner et al. 1994a, b). And RhlC catalyzes the formation of dirhamnolipid from monorhamnolipid and dTDP-L-rhamnose (Rahim et al. 2001). Exogenous expression of those genes in E. coli permits synthesis of rhamnolipids (Ernst 1997; Meyer 1994).

Many microbes are known to be able to degrade petroleum hydrocarbons in aquatic systems such as oceans (http://www.metamicrobe.com/petroleum-microbiology/oil-bioremediation-bacteria.html). Alcanivorax borkumensis is one of the well characterized hydrocarbonoclastic marine bacterium (Akihiro et al. 2003; Yakimov et al. 2007) that produces glucolipids (Naether et al. 2013). P. aeruginosa is also a well characterized oil-eating bacterium (Varjani and Upasani 2016) that produces rhamnolipids (Zhang and Miller 1992). Biosurfactants emulsify crude oil facilitating oil uptake and biodegradation by the oil-eating bacteria.

In this report, we describe a terminal fluorescence labeled (TFL)-RFLP-mediated screening method, from which we obtained a rhamnolipid-producing $P$. aeruginosa ZS1 isolate originated from petroleum sludge in Zhoushan islands. ZS1 isolate produces a mixture of rhamnolipid homologues whose efficacy and capacity against crude oil under various environmental conditions are higher than that of synthetic surfactant SDS. Ex situ bioremediation analysis of ZS1 isolate in shake-flask containing MS medium supplemented with $1 \%$ crude oil as sole carbon source at $30{ }^{\circ} \mathrm{C}$ indicates that $50 \%$ of the crude oil could be consumed in 12 days after growth. We propose that this indigenous ZS1 isolate is suitable for ex situ and in situ bioremediation of petroleum pollutants in Zhoushan islands where national strategic petroleum reservoirs are located. Besides, it has a great potential for large-scale production rhamnolipids using glycerol as sole carbon source.

\section{Materials and methods}

\section{Strain isolation and culture manipulation}

Petroleum sludge was collected from a loading dock of oil tanks at the Sanjiang Ferry Terminal in Zhoushan islands, Zhejiang Province, China and stored at $8{ }^{\circ} \mathrm{C}$. To cultivate microbes originating from sludge, $0.1 \mathrm{mg}$ sludge was added into a Falcon tube containing $3 \mathrm{ml}$ mineral salt (MS, 11 contains: $0.6 \mathrm{~g} \mathrm{Na}_{2} \mathrm{HPO}_{4}, 0.2 \mathrm{~g} \mathrm{KH}_{2} \mathrm{PO}_{4}, 4.0 \mathrm{~g}$ $\mathrm{NaNO}_{3}, 0.3 \mathrm{~g} \mathrm{MgSO}_{4}, 0.01 \mathrm{~g} \mathrm{CaCl}_{2}, 0.01 \mathrm{~g} \mathrm{FeSO}_{4}$ ) (Zajic and Supplison 1972) medium supplemented with $2 \%$ yeast extract (YE) (Thermo Fisher Biochemicals Ltd, Beijing, China) overnight at $30{ }^{\circ} \mathrm{C}$ with shaking for 3 days. The resulting culture was used as seed to inoculate the fresh MS medium supplemented with $2 \%$ yeast extract, $2 \%$ glucose, or $1 \%$ crude oil. Cell growth was monitored by either colorimetric (optical density at the wavelength of $600 \mathrm{~nm}$ ) or gravimetric methodologies (cell dry 
weight). All growth curve analyses in this study were carried out in triplicate. Standard rhamnolipids containing Rha-C10-C10 and Rha-Rha-C10-C10 were used as references (Cat: BMO156, Lot: 14031-2, BALX Biotech Co. Ltd., Tianjin, China).

\section{Surface tension analysis}

Surface tension in supernatant or solution containing purified RL7-11 was determined by using the BZY-B surface tensiometer (Fangrui Instrument Co. Ltd., Shanghai, China) with the du Nouy ring method. It was operated at the room temperature $25{ }^{\circ} \mathrm{C}$ in multiplicate typically between 3 and 5 repeats. Relevant fresh medium was used as control. The instrument was always calibrated using distill water $(72 \mathrm{mN} / \mathrm{m})$ and ethanol $(22 \mathrm{mN} / \mathrm{m})$ prior to use.

In analysis of CMC, 10\% of RL7-11, RL-STD (standard rhamnolipid molecules from BALX Biochem Co. Ltd.) and SDS solutions (w/v) was subjected to twofold serial dilutions. The resulting dilutions were subjected to surface tension analysis. CMC was referred as the minimum concentration required for reducing surface tension to the minimum level. Similarly, in analysis of CMD, serial diluted supernatants were subjected to surface tension analysis. CMD was defined as the maximum dilution required for reducing the surface tension to the minimum level.

\section{Oil-spreading assay}

Oil-spreading assay was applied for estimation of surfactant activity quantitatively following the method by Morikawa et al. (2000) with a minor modification for better preservation of the round shape of the oil-spreading zone (OSZ). Briefly, $50 \mathrm{ml}$ of distilled water was added to a petri dish with a diameter of $15 \mathrm{~cm}$. Subsequently $5 \mu \mathrm{l}$ of the crude oil was added on to the surface of water, which was quickly spread out to form a thin layer. Then, a drop of $20 \mu \mathrm{l}$ crude oil was added and formed the round shaped raft on the surface. To test the surfactant activity, $5 \mu \mathrm{l}$ supernatant was added on to the center of the crude oil raft and waited for $30 \mathrm{~s}$ to allow formation of the oilspreading zone (OSZ). The image of OSZ in petra dish was taken and subjected to NIH ImageJ analysis (http:// www.imagej.nih.gov) for the area of OSZ and DISH in Pixels. The area of OSZ was calculated by the following formula:

$$
\text { AreaOSZ }=\text { Area }_{\text {DISH }}\left(\text { Pixel }_{\text {OSZ }} / \text { Pixel }_{\text {DISH }}\right)
$$

where $\mathrm{Area}_{\mathrm{OSZ}}$ and $\mathrm{Area}_{\mathrm{DISH}}$ are the area of OSZ and DISH (respectively); Pixel $_{\mathrm{OSZ}}$ and Pixel $_{\text {DISH }}$ are the pixels determined by the ImageJ software. A standard curve between quantity of RL7-11 and size of OSZ could be obtained based on this method.

\section{Orcinol-sulfuric acid assay}

A colorimetric orcinol-sulfuric acid assay method (Marchant and Banat 2014) was used to estimate rhamnolipid concentration. Briefly, 1 vol. of supernatant was mixed with 9 vol. of freshly prepared $0.19 \%$ orcinol in $53 \%$ sulfuric acid. The sample was incubated at $80{ }^{\circ} \mathrm{C}$ for $30 \mathrm{~min}$, cooled to RT for $15 \mathrm{~min}$, and subjected to OD measurement at the wavelength of $421 \mathrm{~nm}$. Standard curve between rhamnose and $\mathrm{OD}_{421}$ was prepared using rhamnose (Sigma-Aldrich Co. LLC, Shanghai, China) within a range of $0-50 \mu \mathrm{g} / \mathrm{ml}$. Based on the standard curve, rhamnolipid concentration was estimated as 3 times of the rhamnose concentration according to the OD value (Abalos et al. 2001). In medium supplemented with $2 \%$ glucose or higher, orcinol-sulfuric acid assay may overestimate the concentration of rhamnolipid in supernatant.

\section{Emulsification capacity assay}

Emulsification index E24 analysis was performed according to a procedure reported previously (Cooper and Goldenberg 1987). In brief, equal amount of surfactant solution and crude oil was mixed using a vortex (IKA, Staufen, Germany) at the maximum level for $2 \mathrm{~min}$ and subsequently remained standstill for $24 \mathrm{~h}$. The E24 index was estimated by a ratio between the emulsion volume and total content volume.

\section{Ribosomal RNA gene sequence-based analysis}

To obtain microbial genomic DNA for PCR amplification, mixed or clonal microbial cultures were pelleted by centrifugation and the resulting pellet was resuspended in lysis solution using Genomic DNA Extraction kit (Axygen Scientific Inc., Tewksbury, MA, USA) and genomic DNA was extracted according to the manufacturer's instruction. PCR was performed by using the microbial genomic DNA as template and 16S rDNA-specific primers 27F, $5^{\prime}$-AGAGTTTGATCCTGGCTCAG-3' and 1492R, 5'-GGTTACCTTGTTACGACTT-3') (Moreno et al. 2002). The amplification condition was after the initial denaturation at $94{ }^{\circ} \mathrm{C}$ for $5 \mathrm{~min}, 30$ cycles of $94{ }^{\circ} \mathrm{C}$ for $30 \mathrm{~s}, 55^{\circ} \mathrm{C}$ for $30 \mathrm{~s}$, and $72{ }^{\circ} \mathrm{C}$ for $90 \mathrm{~s}$, and a final extension at $72{ }^{\circ} \mathrm{C}$ for $10 \mathrm{~min}$. The PCR fragment was subjected to sequencing in BGI (BGI, Shenzhen, China). The resulting sequences were compared with NCBI's nucleotide sequences using BLAST tools (http://www.ncbi.nlm.nih. gov). Top hit sequences were downloaded and included in alignment analysis using CLUSTAL X 2.0 software (Larkin et al. 2007) and phylogenetic tree construction by MEGA 6.0 software (Tamura et al. 2013).

\section{TFL-RFLP analysis}

For TFL-RFLP and RFLP analysis, SybrGreen labeled 27F primer was used in PCR amplification of $16 \mathrm{~S}$ 
rDNA sequences. The resulting fragment was HhaI digested and separated on an 8\% DNA PAGE gel. Gel image was recorded in the Gel Imaging System Tanon 5200 (Tanon Scientific Inc., Shanghai, China) in a SybrGreen fluorescence channel. For RFLP analysis, TFL-RFLP gel was imaged after ethidium bromide staining.

\section{qRT-PCR analysis}

For analysis of transcriptional profiles of RhlA, RhlB, and RhlC genes, samples at $0,10,20,35$, and $60 \mathrm{~h}$ after growth in MS medium supplemented with $2 \%$ glucose. The transcript sequences were based on the study (Zhang et al. 2012) and sequence-specific primer pairs for RhlA, RhlB, and RhlC were RhlA_F (5'-GAAATCCTC CTGGCGCTGAT- $3^{\prime}$ ) and RhIA_R (5'-ACGGTCTCGTT GAGCAGATG-3'), RhlB_F(5'-CGCATCGCTCACGAG AAGTA-3') and RhlB_R (5'-GTCGAGTCCCTGGTTG AAGG-3'), and RhlC_F (5'-CGTGCTGGTGGTACTG TTCA-3') and RhlC_R (5'-GTCGAGTCCCTGGTTGA AGG-3'), respectively. One-step quantitative reverse transcription PCR were performed using the Ultra SyGr One Step RT-PCR kit (Thermo Fisher Biochemicals Ltd) on a ViiA 7 Real-Time PCR System (AB Scientific, USA) machine following the manufacturer's instruction. The RpoD was used as control for constitutively transcribe gene according to Zhang et al. (2012) and its sequence-specific primers was rpoD_F (5'-GGGCGAAG AAGGAAATGGTC- $3^{\prime}$ ) and rpoD_R (5'-CAGGTGGC GTAGGTGGAGAA- $3^{\prime}$ ). Transcription levels were 0-normalized.

\section{Purification of rhamnolipids}

Extraction of rhamnolipids was performed according to the procedure previously reported (Chandankere et al. 2013). In brief, cell-free supernatant was acidified to precipitate rhamnolipids by addition of $6 \mathrm{~N} \mathrm{HCl}$ to $\mathrm{pH} 2$ and kept at room temperature overnight. The precipitated rhamnolipids collected by centrifugation at $4000 \mathrm{rpm} 25{ }^{\circ} \mathrm{C}$ for $20 \mathrm{~min}$. The resulting pellet was resuspended in solution of chloroform: methanol with a ratio of 2:1 and the chloroform fraction was recovered and evaporated using a distiller for chloroform recycling. This extraction of rhamnolipids was repeated for at least three times using chloroform: methanol 2:1 solution. The resulting brownish semisolid rhamnolipids were dried in oven at $70{ }^{\circ} \mathrm{C}$ overnight. The purified rhamnolipids were used for biosurfactant activity and chemical composition analyses. Rhamnolipids were resolved in distill water for surface tension and emulsification analyses and resolved in chloroform for TLC and LC-MS/MS analyses.

\section{Thin layer chromatographic analysis}

For thin-layer chromatographic (TLC) analysis, $0.1 \mathrm{~g}$ purified-rhamnolipids was resolved in $1 \mathrm{ml}$ chloroform. Approx. $100 \mu \mathrm{g}$ rhamnolipids solution was loaded on to a TLC plate (Marine Biotech Co., Qingdao, China). As control, $50 \mu \mathrm{g}$ of the standard rhamnolipids rha- $\mathrm{C}_{10}-\mathrm{C}_{10}$ and rha-rha- $\mathrm{C}_{10}-\mathrm{C}_{10}$ (Sigma/Aldrich, USA) was loaded. The plates were developed in the solution of chloroform: methanol: acetic acid at a ratio of 65:15:2 and exposed to iodine vapor for visualization of glycolipids.

\section{LC-MS/MS}

To analyze the composition of the rhamnolipids produced by the ZS1, its purified rhamnolipids was resolved in chloroform at a concentration of $0.1 \mathrm{~g} / \mathrm{ml}$. LC-MS/ MS analysis of the rhamnolipids was performed using the Water UPLC (Waters Corp., Milford, MA, USA) system equipped with the Aquity UPLC Beh- $\mathrm{C}_{18}$ column $(1.7 \mu \mathrm{m}, 2.1 \times 50 \mathrm{~mm}$; Waters Corp.) coupled with the AB Triple TOF 5600 plus System (AB Sciex, Framingham, USA). In LC analysis, the mobile phases $0.1 \%$ formic acid-water (A) and $0.1 \%$ formic acid-acetonitrile (B) were employed. Linear gradient programs were set as follows, 0/20, 20/95,35/95, 36/20 (min/B\%); Sample injection volume was $2 \mu \mathrm{l}$; Column oven temperature set as $35^{\circ} \mathrm{C}$; Flow rate was $0.4 \mathrm{ml} / \mathrm{min}$; and the UV detector was set at the wavelength of $220 \mathrm{~nm}$. In mass spectrometry analysis, MS scan range was set at $\mathrm{m} / z$ 100-2000 in negative ion mode with a source voltage of $-4.5 \mathrm{kV}$ and source temperature at $550{ }^{\circ} \mathrm{C}$. The pressure of Gas 1 (Air) and Gas 2 (Air) were set to 50 psi. The pressure of Curtain Gas (N2) was set to 35 psi. Maximum allowed error was set to $\pm 5 \mathrm{ppm}$. Declustering potential (DP) was $100 \mathrm{~V}$; collision energy (CE) at $10 \mathrm{~V}$. For MS/MS acquisition mode, the parameters were almost the same except that the collision energy (CE) was set at $50 \pm 20 \mathrm{~V}$, ion release delay (IRD) at 67, ion release width (IRW) at 25. Analyst TF 1.6 and Peakview 1.2 software (AB Sciex, Framingham, USA) were used for data acquisition and data analysis, respectively.

\section{Analyses of surfactant activity of RL under various environmental conditions}

To compare the stability of biosurfactant RL7-11 and synthetic surfactant SDS under conditions with various $\mathrm{pH}$, salinities, and temperatures, aliquots of $0.12 \mathrm{~g} / \mathrm{l} \mathrm{RL7-}$ 11 and $1.5 \mathrm{~g} / \mathrm{l} \mathrm{SDS}$ were subjected to various treatments according to the method described previously (Chandankere et al. 2013) prior to surface tension and emulsification index E24 analyses. For stability under various $\mathrm{pH}$, aliquots of $20 \mathrm{ml}$ surfactants were adjusted to $\mathrm{pH} 4.0$, $6.0,8.0,10.0$ and 12.0 using $6 \mathrm{M} \mathrm{NaOH}$ or $6 \mathrm{M} \mathrm{HCl}$ prior 
to surface tension and emulsification index analyses. For stability under various salinities, equal volume of twofold concentrated surfactant and $\mathrm{NaCl}$ solutions were mixed to have the final concentration of RL7-11 at $0.12 \mathrm{~g} / \mathrm{l}$ and $\mathrm{NaCl}$ at $0,4,8$, and $12 \%$ in each sample prior to surfactant activity analyses. For stability under various temperatures, aliquots were incubated at $25,40,60,80$, and $100{ }^{\circ} \mathrm{C}$ for 30 min prior to analyses of surfactant activity. All experiments were performed in triplicate. Commercial rhamnolipids Rha-C10-C10 and Rha-Rha-C10-C10 (RL-STD) (BALX Biotech Co. Ptd., Tianjin, China) was also used in the text at a concentration of $0.12 \mathrm{~g} / \mathrm{l}$ as that of RL7-11.

\section{Analysis of the rate for crude oil consumption by ZS1}

To estimate the consumption rate of crude oil or hexadecane by ZS1 isolate, growth curve analysis of ZS1 in shake-flask at $30{ }^{\circ} \mathrm{C} 180 \mathrm{rpm}$ containing ME medium supplemented with $1 \%$ crude oil or hexadecane was performed. Total crude oils in the first week (due to the presence of adhesive oil residues at flask wall) of growth were determined by using replicates. Culture in flask was poured out to a fresh tube, followed by centrifugation to separate the pellet and supernatant (including floating oils). The resulting pellet was subjected to cell dry weight determination; the floating oils were poured back to the initial flask and extracted together with hexane for determination of unemulsified oils. The remaining supernatant was extracted with equal volume of hexane for determination of emulsified crude oil. A week after growth (no apparent adhesive oil residues), $10-20 \mathrm{ml}$ culture was sampled for determination of cell dry weight (cell mass), floating oils and emulsified oils at various time points in triplicate. All measurements were carried out in triplicate. Total amount of crude oil is calculated as the sum of unemulsified and emulsified oils.

\section{Information related to strain deposition and 165 rDNA sequence submission}

The sludge-derived rhamnolipid-producing $P$. aeruginosa ZS1 isolate described in this study was deposited in China General Microbiological Culture Collection Center (CGMCC) with the identity number of 13656 . Its $16 \mathrm{~S}$ rDNA sequence was submitted to GenBank at the National Center for Biotechnology Information (NCBI) with the accession number of KY437088.

\section{Results}

Isolation of glucose-enriched biosurfactant-producing microbes derived from oil sludge

Petroleum sludge was collected near the Sanjiang Ferry Terminal located in Zhoushan islands, Zhejiang Province, China. Approx. $0.1 \mathrm{~g}$ of petroleum sludge was resuspended in the minimal salt (MS) medium (Zajic and Supplison 1972) supplemented with $2 \%$ yeast extract. The resulting culture was utilized as seed to inoculate fresh MS medium supplemented with $2 \%$ glucose as sole carbon source. Cell-free supernatant of cultures was subjected to surface tension analysis using the du Nouy ring method (Butt et al. 2003; du Noüy 1925) in triplicate (see "Materials and methods"). Surface tension of the culture supernatant at start was $\sim 62 \mathrm{mN} / \mathrm{m}$. After growth for $32 \mathrm{~h}$, surface tension of supernatant was reduced to $37 \mathrm{mN} / \mathrm{m}$ (Fig. 1a), indicating that biosurfactants were produced in microbial culture derived from oil sludge.

To investigate the dynamics of microbial populations in cultures derived from oil sludge, we performed the rapid terminal fluorescence-labeled (TFL)-RFLP analysis to monitor the dynamics of individual microbial populations in cultures of MS medium supplemented with glucose (see "Materials and methods"). In this TFL-RFLP analysis, $16 \mathrm{~S}$ rRNA gene sequences of the sludge-derived microbes were amplified by the standard primer pairs (fluorescence labeled 27F, 5'-AGAGTTTGATCCTGGCTCAG-3'; 1492R, 5'-GGTTACCTTGTTACGACTT-3') (Moreno et al. 2002) and subsequently digested with restriction enzyme Hhal. Each microbial species possessed only one fluorescence labeled-fragment with a length depending on the position of the first HhaI site to the labeled primer. The analysis showed that, prior to growth in MS medium supplemented with $2 \%$ glucose, three major species with the characteristic of RFLP fluorescence fragments of 270, $380 \mathrm{bps}$, and $1.2 \mathrm{~kb}$ in length were present in starting culture at $0 \mathrm{~h}$ (Fig. 1b, see arrowhead). After growth for $64 \mathrm{~h}$ in MS medium supplemented with glucose, a major species with the characteristic of RFLP fluorescence fragment of 170 bps in length appeared (Fig. 1b, see arrow), while three initial species diminished.

To investigate whether the species with the characteristic of RFLP fluorescence fragment of $170 \mathrm{bps}$ in length was responsible for biosurfactant production, single colonies from the culture after growth for $64 \mathrm{~h}$ in MS medium supplemented with glucose were obtained. Seven randomly chosen colonies grown in MS medium supplemented with $2 \%$ glucose were subjected to TFL-RFLP analysis. All seven selected colonies exhibited a characteristic of RFLP fluorescence fragment of $170 \mathrm{bps}$ in length (Fig. 1c). Biosurfactant activity in supernatant of the isolate cultures were obvious (Fig. 1d). This result suggested that a biosurfactant-producing microbial species from oil sludge was enriched by glucose as sole carbon source.

\section{Biosurfactant-producing microbe ZS1 isolated from oil sludge belongs to the group of $P$. aeruginosa}

To investigate the species of the biosurfactant-producing microbe isolated from oil sludge, one of the seven isolates 

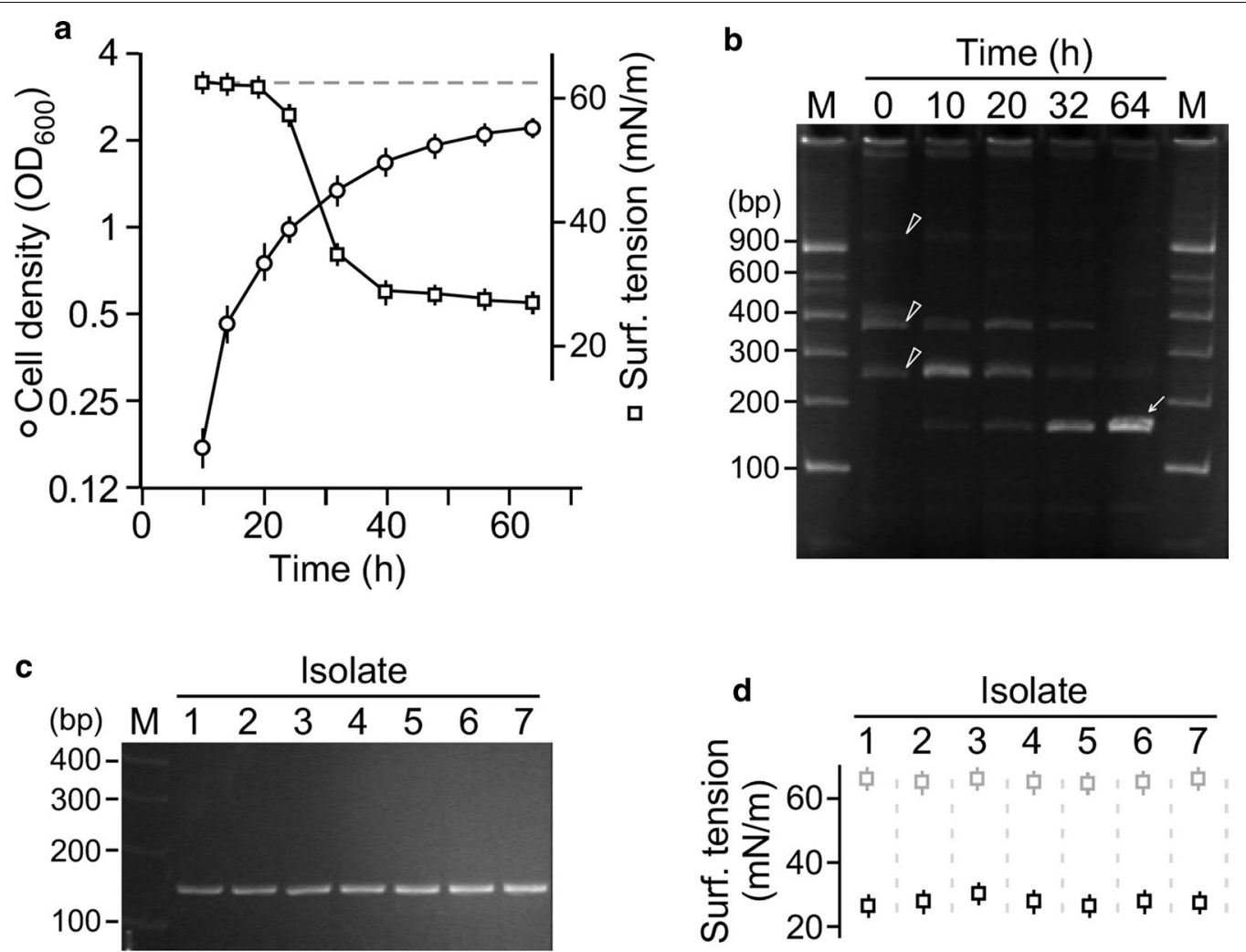

Fig. 1 Identification of biosurfactant activity in mixed microbial cultures derived from oil sludge. a Surfactant activity is detected in supernatant of cultures originated from oil sludge. $X$ - and $Y$-axis indicate the time and cell density $\left(\mathrm{OD}_{600}\right)$ of the culture. Inset indicates the surface tension $(\mathrm{mN} / \mathrm{m})$ at various time points. The horizontal dash line indicates the surface tension of the fresh medium. $\mathbf{b}$ Dynamics of individual microbial populations. TFL-RFLP analysis of oil sludge-derived cultures at various time points. Arrowhead and arrow indicate the initial (at $0 \mathrm{~h}$ ) and final (at $64 \mathrm{~h}$ ) microbial populations, respectively. c Characterization of microbial isolates from cultures $64 \mathrm{~h}$ after growth. TFL-RFLP analysis of individual isolates, identical to those observed at $64 \mathrm{~h}$ in (B). d Biosurfactant activity produced by individual isolates. Surface tension of individual isolate cultures (black square) and fresh medium (grey square)

(or ZS1 isolate) was subjected to $16 \mathrm{~S}$ rDNA sequence analysis. For this reason, the $16 \mathrm{~S}$ rDNA sequence was PCR amplified with sequence-specific primers (Moreno et al. 2002). The resulting DNA fragment was subjected to nucleotide sequencing analysis and followed by phylogenic analysis using CLUSTAL X 2.0 (Larkin et al. 2007) and MEGA 6.0 software (Tamura et al. 2013). Based on sequence-based analysis, ZS1 isolate appeared to fall into the group of $P$. aeruginosa (Fig. 2a). Hence, it was designated as $P$. aeruginosa ZS1.

Many members of the $P$. aeruginosa group isolated from either patients or oil sludge were known to produce rhamnolipids (Muller et al. 2012). Biosynthesis of rhamnolipids depended on three key enzymes RhlA, RhlB, and RhlC (Ochsner et al. 1994a, b; Rahim et al. 2001; Rehm et al. 1998). To test whether transcription of these genes in the ZS1 isolate was induced upon growth in medium with glucose as sole carbon source, we performed quantitative reverse transcriptase (qRT) - PCR analysis. To this end, we found that transcription of all three enzymes-encoding genes was induced with the peak at $35 \mathrm{~h}$ after growth in MS medium supplemented with $2 \%$ glucose (Fig. $2 \mathrm{~b}$ ). This result was consistent with the observation that biosurfactant activity appeared at $35 \mathrm{~h}$ after growth in medium with glucose as sole carbon source (see Fig. 1).

Rhamnolipids produced by ZS1 isolate consists of 7 monoand 11 di-rhamnolipids homologues

Rhamnolipids are glycolipid molecules that consist of one or two L-rhamnose sugars and one or two $\beta$-hydroxyalkanoic acids. To investigate if $P$. aeruginosa ZS1 isolate produced rhamnolipids that was responsible for the biosurfactant activity, molecules in $\sim 41$ of cell-free supernatant containing biosurfactant activity were enriched through acidification and precipitation followed by extraction with chloroform/methanol (see "Materials and methods"). After evaporation of solvent, the resulting semi-solid materials were resolved in chloroform at a concentration of $0.1 \mathrm{mg} / \mathrm{ml}$ for TLC analysis. It was clear that the 

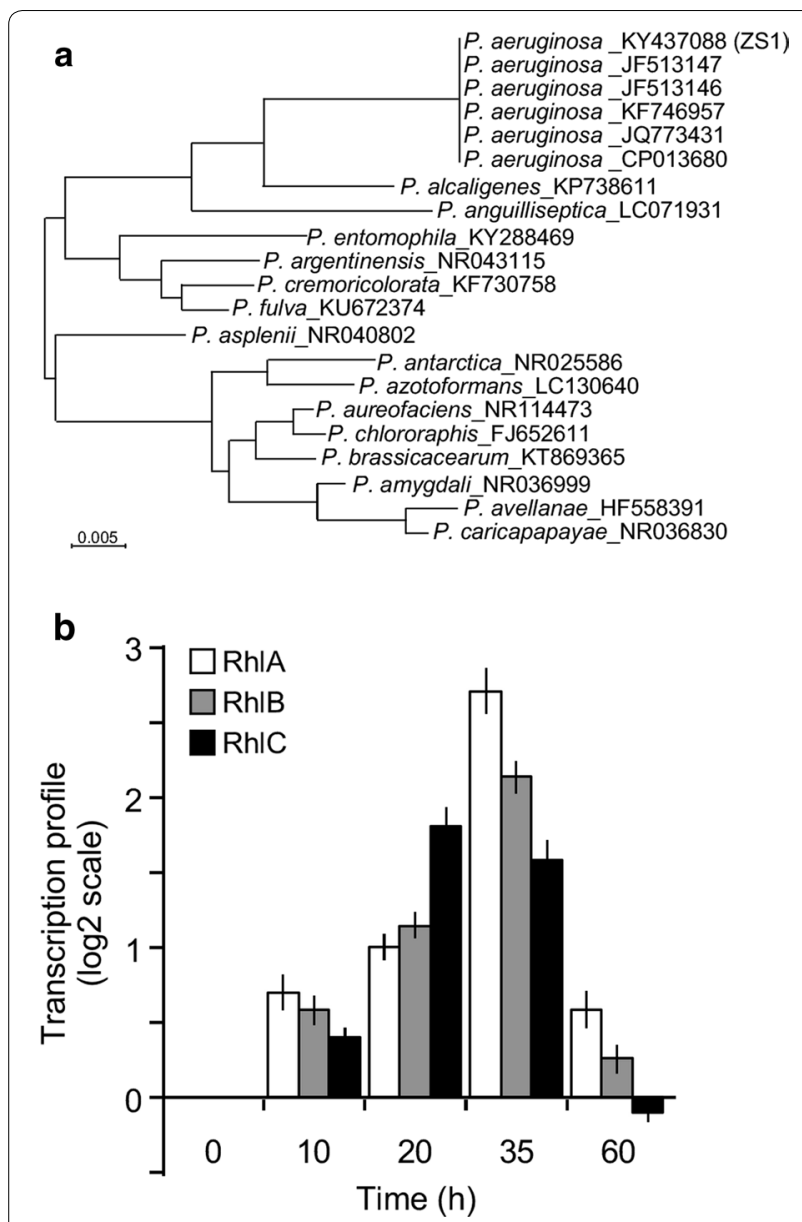

Fig. 2 Biosurfactant-producing ZS1 isolate belongs to the group of Pseudomonas aeruginosa. a The $16 \mathrm{~S}$ rDNA sequence-based phylogenic analysis of the ZS1 isolate. The isolate is indicated as ZS1 in parentheses, whose nucleotide sequence is available in Genebank (https://www.ncbi.nlm.nih.gov/genbank) with the Accession Number KF668476). b Transcription of rhamnolipid synthesis genes is induced in medium with glucose as sole carbon source. qRT-PCR analysis of RhIA, RhIB, and RhIC gene expression at various time-points after ZS1 growth in MS medium supplemented with glucose

rhamnolipid mixture contained both mono- and di-rhamnolipid homologues according to standard rhamnolipid molecules of rha- $C_{10}-C_{10}$ and rha-rha- $C_{10}-C_{10}$ (Fig. 3a).

To investigate the composition of the rhamnolipid mixture produced by ZS1 isolate, supernatant extracts were subjected to LC-MS/MS analysis. To this end, the analysis showed that the mixture contained a total of 7 mono-rhamnolipid and 11 di-rhamnolipid homologues with a range of alkyl chain lengths from $\mathrm{C}_{6}$ to $\mathrm{C}_{16}$ (Fig. 3b, c). Therefore, we designated the whole mixture of rhamnolipids produced by $P$. aeruginosa $\mathrm{ZS} 1$ as RL7-11. Of the 7 mono-rhamnolipid homologues, 4 showed to have isoforms (rha- $\mathrm{C}_{8}-\mathrm{C}_{10} /$ rha- $\mathrm{C}_{10}-\mathrm{C}_{8}$, rha$\mathrm{C}_{10}-\mathrm{C}_{12: 1} /$ rha- $\mathrm{C}_{12: 1}-\mathrm{C}_{10}$, rha- $\mathrm{C}_{10}-\mathrm{C}_{12} /$ rha- $\mathrm{C}_{12}-\mathrm{C}_{10}$, and rha- $\left.\mathrm{C}_{10}-\mathrm{C}_{14: 1} / \mathrm{rha}-\mathrm{C}_{14: 1}-\mathrm{C}_{10}\right)$, 2 had identical alkyl chain length (rha- $\mathrm{C}_{8}-\mathrm{C}_{8}$ and rha- $\mathrm{C}_{10}-\mathrm{C}_{10}$ ), and 1 showed no isoform detected (rha- $\mathrm{C}_{10}-\mathrm{C}_{6}$ ).

On the other hand, of the 11 di-rhamnolipid homologues, 6 showed to have isoforms (rha-rha- $\mathrm{C}_{8}-\mathrm{C}_{10}$ / rha-rha- $\mathrm{C}_{10}-\mathrm{C}_{8}$,rha-rha- $\mathrm{C}_{10}-\mathrm{C}_{12: 1}$ /rha-rha- $\mathrm{C}_{12: 1}-\mathrm{C}_{10}$, rha-rha$\mathrm{C}_{10}-\mathrm{C}_{12} /$ rha-rha- $\mathrm{C}_{12}-\mathrm{C}_{10}$, and rha-rha- $\mathrm{C}_{10}-\mathrm{C}_{14: 1} /$ rharha- $\mathrm{C}_{14: 1} \mathrm{C}_{10}$, rha-rha- $\mathrm{C}_{12}-\mathrm{C}_{12: 1} /$ rha-rha- $\mathrm{C}_{12: 1}-\mathrm{C}_{12}$, and rha-rha- $\mathrm{C}_{10}-\mathrm{C}_{16: 1} /$ rha-rha- $\left.\mathrm{C}_{16: 1}-\mathrm{C}_{10}\right)$, 3 had identical alkyl chain length (rha-rha- $\mathrm{C}_{8}-\mathrm{C}_{8}$, rha-rha- $\mathrm{C}_{10}-\mathrm{C}_{10}$, and rharha- $\mathrm{C}_{12}-\mathrm{C}_{12}$ ), and 2 had no isoforms detected (rha-rha$\mathrm{C}_{8}-\mathrm{C}_{12: 1}$ and rha-rha- $\mathrm{C}_{10}-\mathrm{C}_{10: 1}$ ). We found that, of the 7 mono- and 11 di-rhamnolipid homologues, 2 rhamnolipid homologues, namely the rha- $\mathrm{C}_{10}-\mathrm{C}_{6}$ and rharha- $\mathrm{C}_{16: 1}-\mathrm{C}_{10}$ (or rha-rha- $\mathrm{C}_{10}-\mathrm{C}_{16: 1}$ ), were not previously identified. Based on the relative abundance of various homologues, common rhamnolipid homologues rha-rha$\mathrm{C}_{10}-\mathrm{C}_{10}$ and rha- $\mathrm{C}_{10}-\mathrm{C}_{10}$ were the top 2 most abundant molecules in the RL7-11 mixture, accounting for $37.4 \%$ of the total rhamnolipids (Table 1).

\section{Rhamnolipid yield in ZS1 isolate is affected by concentration of supplemented carbon sources}

To investigate whether rhamnolipid yield in ZS1 isolate was altered by change of glucose supplement concentration in MS medium, we performed analyses of cell biomass and biosurfactant activity by ZS1 in MS medium supplemented with various concentrations of glucose (see "Materials and methods"). We found that the logphase growth rate of the cultures was positively correlated with glucose concentrations from 0.12 to $2 \%$, but not $4 \%$ (Fig. 4a). On the other hand, the cell density at the onset of stationary-phase was correlated with the glucose concentration from $0.12 \%$ up to $4 \%$. This result indicted that increase of glucose concentrations enhanced the maximum cell density of the ZS1 culture.

Biosurfactant activity in supernatant of cultures with various concentrations of glucose supplements at different time points during growth was determined using oil-spreading assay. We found that the surfactant activity was detected at the early log-phase and soon reached maximal level at the onset of stationary phase (Fig. 4b). Oil-spreading analyses indicated that areas of oil-spreading zone in supernatant of ZS1 cultures containing 0.5, 1,2 and $4 \%$ glucose supplements were $25,50,170$, and $250 \mathrm{~cm}^{2} / \mu \mathrm{l}$, respectively. Based on a standard curve (see "Materials and methods"), the sizes of oil-spreading zone could be approximated to concentrations of rhamnolipids RL7-11 at 4.7, 9.3, 30, and $44 \mathrm{~g} / \mathrm{l}$.

We found that ZS1 isolate in MS medium supplemented with $2 \%$ glucose showed the maximum level of glucose usage or carbon yield of $26.8 \%$ mol rhamnolipid/ mol glucose compared to that of cultures with $0.5,1$, and 


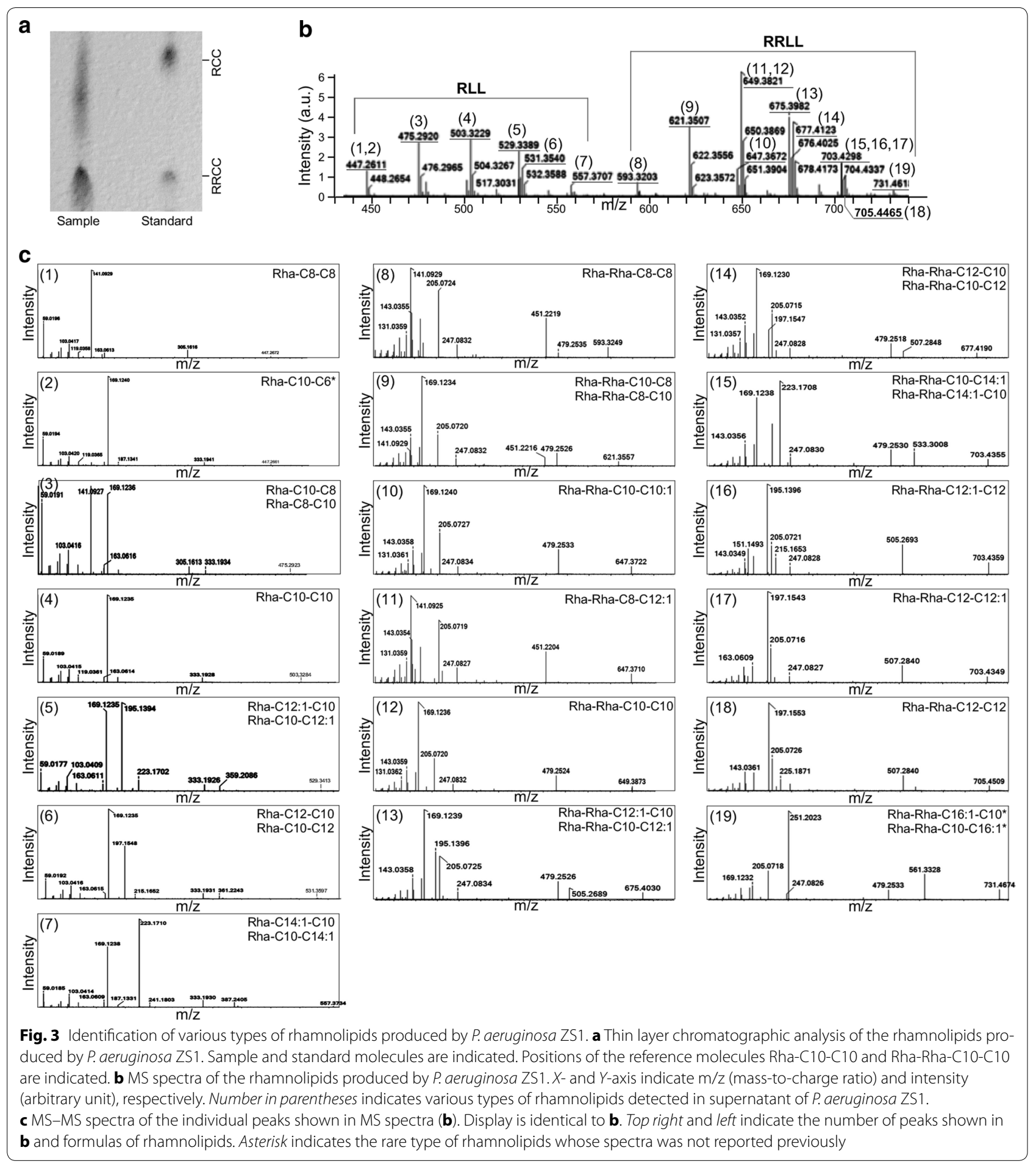

4\% glucose supplements (Fig. 4c). Additionally, ZS1 culture with $2 \%$ glucose supplement exhibited the maximum productivity of $827 \mathrm{mg} / \mathrm{l} \mathrm{h}$ compared to that of cultures with $0.5,1$, and $4 \%$ glucose supplements (Fig. 4 d).
To investigate whether ZS1 isolate produced rhamnolipids using glycerol as sole carbon source, we analyzed the growth of ZS1 in MS medium supplemented with 1, 2, and 4\% glycerol. Maximum yield of ZS1 cultures 
Table 1 Composition of rhamnolipids RL7-11 produced by $P$. aeruginosa ZS1

\begin{tabular}{|c|c|c|c|c|c|}
\hline No. & {$[\mathrm{M}-\mathrm{H}]^{-}(\mathrm{m} / \mathrm{z})$} & RL7-11 components & Molecular formula & Relative level (\%) & Rank \\
\hline 1 & 447.3 & Rha-C8-C8 & $\mathrm{C} 22 \mathrm{H} 40 \mathrm{O} 9$ & 1.47 & 16 \\
\hline 2 & 447.3 & Rha-C10-C6 & $\mathrm{C} 22 \mathrm{H} 40 \mathrm{O} 9$ & 2.78 & 9 \\
\hline 3 & 475.3 & Rha-C10-C8/Rha-C8-C10 & $\mathrm{C} 24 \mathrm{H} 44 \mathrm{O} 9$ & 10.11 & 4 \\
\hline 4 & 503.3 & Rha-C10-C10 & $\mathrm{C} 26 \mathrm{H} 48 \mathrm{O} 9$ & 17.74 & 2 \\
\hline 5 & 529.3 & Rha-C10-C12:1/Rha-C12:1-C10 & $\mathrm{C} 28 \mathrm{H} 50 \mathrm{O} 9$ & 2.36 & 13 \\
\hline 6 & 531.4 & Rha-C10-C12/Rha-C12-C10 & $\mathrm{C} 28 \mathrm{H} 52 \mathrm{O} 9$ & 4.72 & 6 \\
\hline 7 & 557.4 & Rha-C10-C14:1/Rha-C14:1-C10 & $\mathrm{C} 30 \mathrm{H} 54 \mathrm{O} 9$ & 0.85 & 18 \\
\hline 8 & 593.3 & Rha-Rha-C8-C8 & $\mathrm{C} 28 \mathrm{H} 50 \mathrm{O} 13$ & 1.79 & 15 \\
\hline 9 & 621.4 & Rha-Rha-C10-C8/Rha-Rha-C8-C10 & $\mathrm{C} 30 \mathrm{H} 54 \mathrm{O} 13$ & 11.80 & 3 \\
\hline 10 & 647.4 & Rha-Rha-C10-C10:1 & $\mathrm{C} 32 \mathrm{H} 56 \mathrm{O} 13$ & 1.80 & 14 \\
\hline 11 & 647.4 & Rha-Rha-C8-C12:1 & $\mathrm{C} 32 \mathrm{H} 56 \mathrm{O} 13$ & 2.71 & 11 \\
\hline 12 & 649.4 & Rha-Rha-C10-C10 & $\mathrm{C} 32 \mathrm{H} 58 \mathrm{O} 13$ & 19.66 & 1 \\
\hline 13 & 675.4 & Rha-Rha-C12:1-C10/Rha-Rha-C10-C12:1 & $\mathrm{C} 34 \mathrm{H} 60013$ & 2.37 & 12 \\
\hline 14 & 677.4 & Rha-Rha-C12-C10/Rha-Rha-C10-C12 & $\mathrm{C} 34 \mathrm{H} 62 \mathrm{O} 13$ & 8.28 & 5 \\
\hline 15 & 703.4 & Rha-Rha-C10-C14:1/Rha-Rha-C14:1-C10 & $\mathrm{C} 36 \mathrm{H} 64 \mathrm{O} 13$ & 3.62 & 8 \\
\hline 16.1 & 703.4 & Rha-Rha-C12:1-C12 & $\mathrm{C} 36 \mathrm{H} 64 \mathrm{O} 13$ & 0.94 & 17 \\
\hline 16.2 & 703.4 & Rha-Rha-C12-C12:1 & $\mathrm{C} 36 \mathrm{H} 64 \mathrm{O} 13$ & 3.77 & 7 \\
\hline 17 & 705.5 & Rha-Rha-C12-C12 & $\mathrm{C} 36 \mathrm{H} 66 \mathrm{O} 13$ & 2.72 & 10 \\
\hline 18 & 731.5 & Rha-Rha-C10-C16:1/Rha-Rha-C16:1-C10 & $\mathrm{C} 38 \mathrm{H} 68 \mathrm{O} 13$ & 0.50 & 19 \\
\hline
\end{tabular}

supplemented with 1,2 , and $4 \%$ glycerol was $7.5,18.5$ and $30 \mathrm{~g} / \mathrm{l}$ (respectively) based on both oil-spreading zone (Morikawa et al. 2000) and orcinol sulfuric acid methods (Abalos et al. 2001) (Fig. 4e). Given glycerol as by-product of biodiesel production, using crude glycerol by-product could reduce the cost of rhamnolipid production.

We determined rhamnolipid content in cultures supplemented with 1,2 and $4 \%$ glucose using both oilspreading zone method and orcinol sulfuric acid method. The level of rhamnolipid determined by orcinol sulfuric method was found to be much higher than that by oil-spreading zone when concentration of glucose supplements was $2 \%$ or higher $(\mathrm{p}<0.01)$ (Fig. $4 \mathrm{f})$. This result suggested that glucose residue remained in culture medium might contribute to the overestimation of rhamnolipid yield. Hence, rhamnolipid levels in glucosecontaining media were estimated using oil-spreading method throughout this study.

\section{Rhamnolipid mixture RL7-11 is highly effective compared to the chemically synthesized SDS}

Critical micelle concentration $(\mathrm{CMC})$ defined the minimum concentration required for micelle formation, indicating the efficacy of surfactants. To compare the efficacy between rhamnolipid mixture RL7-11 and chemically synthetic surfactant SDS, we first determined CMC for RL7-11 and SDS. To this end, 10\% (w/v) initial solutions of RL7-11 and SDS were subjected to twofold serial dilutions and subsequently measurement of surface tension using the du Nouy ring method (du Noüy 1925). The analyses indicated that rhamnolipids RL7-11 reduced surface tension to the minimum level of $26.4 \mathrm{mN} / \mathrm{m}$ at a concentration of $0.12 \mathrm{~g} / \mathrm{l}$, or CMC (Fig. $5 \mathrm{a}$ ). On the other hand, the synthetic surfactant SDS showed a CMC of $1.5 \mathrm{~g} / \mathrm{l}$ that reduced surface tension to the minimum level of $28.9 \mathrm{mN} / \mathrm{m}$. We noted that reference rhamnolipids containing rha-C10-C10 and rha-rha-C10-C10 (or RL-STD) whose CMC was $0.1 \mathrm{~g} / \mathrm{l}$, a bit lower than that of RL7-11. This result indicated that rhamnolipids RL711 and RL-STD exhibited higher capability in terms of reducing surface tension $(26.4 \mathrm{mN} / \mathrm{m}$ versus $28.9 \mathrm{mN} / \mathrm{m})$ at lower concentration of compounds $(0.12$ or $0.1 \mathrm{~g} / \mathrm{l}$ versus $1.5 \mathrm{~g} / \mathrm{l}$ ) compared to the synthetic surfactant SDS.

We subsequently determined emulsification E24 indexes of surfactants in various concentrations to compare the emulsification capacity against crude oil between RL7-11, RL-STD, and SDS. Our analysis indicated that RL7-11 and RL-STD reached the maximum E24 index of $100 \%$ at the minimum concentration of $1.2 \mathrm{~g} / \mathrm{l}$, whereas SDS reached the maximum E24 index of $74 \%$ at the minimum concentration of $5 \mathrm{~g} / \mathrm{l}$ (Fig. 5b). This result indicated that RL7-11 and RL-STD exhibited higher emulsification capacity against crude oil than did SDS.

We next compared the stability of surfactant activity such as surface tension reduction and emulsion formation and maintenance between RL7-11, RL-STD, and SDS under various environmental conditions. To ensure the adequate comparison, concentrations of RL7-11, 

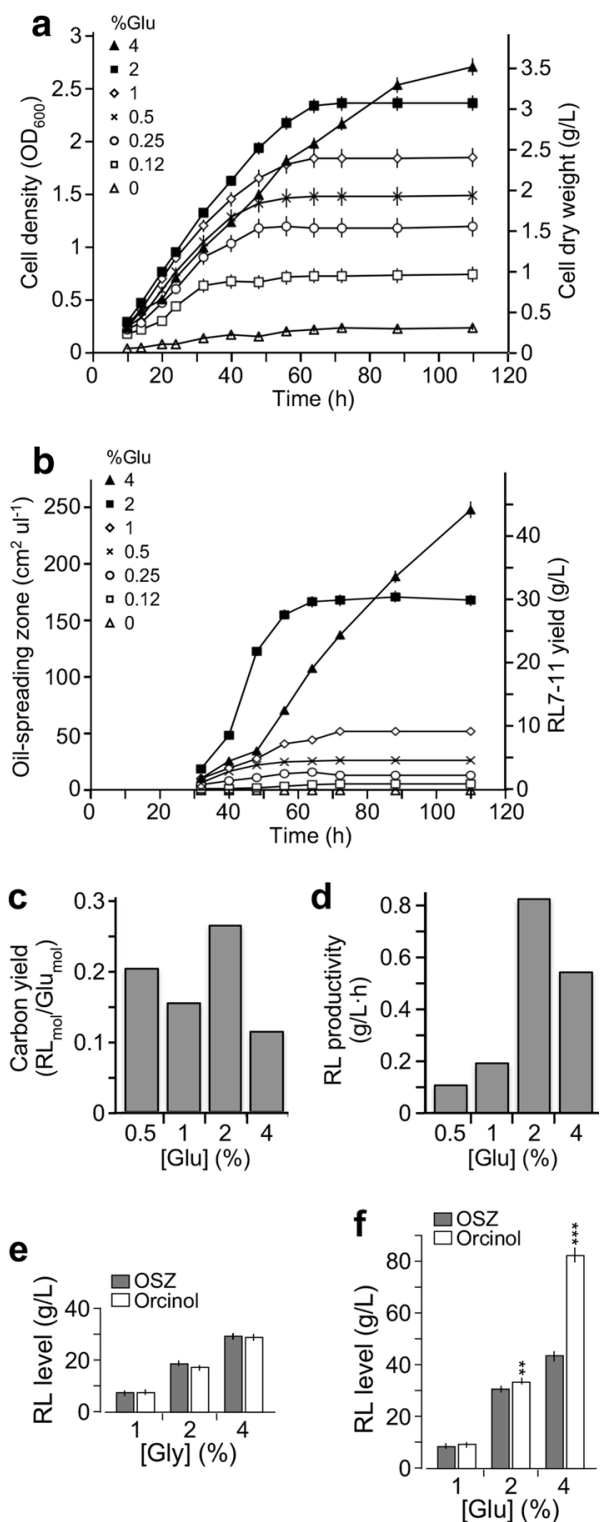

Fig. 4 Rhamnolipid yield by ZS1 isolate under various growth conditions. a Growth curve analysis of ZS1 cultures with various amounts of glucose supplements. $X$ - and $Y$-axis indicate time in hour (h) and cell concentration in optical density (left) or cell dry weight (right), respectively. b Change of surfactant activities during cell growth. $X$ - and $Y$-axis indicate time $(\mathrm{h})$ and oil-spreading zone ( $\mathrm{cm}^{2} / \mu \mathrm{l}$, left) or RL7-11 concentration (g/l, right). c Carbon yield or ratio between product RL7-11 and carbon source glucose in ZS1 cultures with various glucose supplements. $X$ - and $Y$-axis indicate supplement glucose concentration and carbon yield in $\mathrm{RL}_{\text {mol }} / \mathrm{Glu}_{\text {mol }}$, respectively. d RL7-11 productivity in ZS1 cultures with various glucose supplements. $X$ - and $Y$-axis indicate supplemented glucose concentration and RL7-11 productivity in g/l h, respectively. e Quantification of rhamnolipids by oil-spreading assay (OSZ) or orcinol method (Orcinol) in cultures with various glycerol supplement. No significantly differences between the two methods is observed. $\mathbf{f}$ Quantification of rhamnolipids by oil-spreading assay (OSZ) or orcinol method (Orcinol) in cultures with various glucose supplement. Significant difference between the two methods is apparent. Asterisk indicates the significant difference between the results by OSZ and Orcinol
RL-TSD, and SDS at 0.12, 0.12, and 5 g/l (respectively) were employed in the analysis. RL7-11 and RL-STD at the concentration of $0.12 \mathrm{~g} / \mathrm{l}$ under optimal conditions (pH7, $25{ }^{\circ} \mathrm{C}$, without salt) reduced surface tension to $26.5 \mathrm{mN} / \mathrm{m}$ and exhibited emulsification E24 index of $76 \%$ against crude oil, while SDS at $5 \mathrm{~g} / \mathrm{l}$ reduced surface tension to $29 \mathrm{mN} / \mathrm{m}$ and displayed emulsification E24 index of $74 \%$.

It was clear that RL7-11 displayed a consistent activity in reducing surface tension to the minimum level and maintaining emulsion under wide ranges of $\mathrm{pH}$ ( $\mathrm{pH} 4-12)$, salinity $(0-12 \% \mathrm{NaCl})$, and temperature $\left(25-100{ }^{\circ} \mathrm{C}\right)$ (Fig. $\left.5 \mathrm{c}-\mathrm{e}\right)$. In contrast, SDS showed activity within a relatively narrow range of $\mathrm{pH}(6-8)$, salinity $(0-4 \% \mathrm{NaCl}$ for emulsification; $0-8 \% \mathrm{NaCl}$ for surface tension reduction), and temperature $\left(25-60{ }^{\circ} \mathrm{C}\right.$ for emulsification, $25-80{ }^{\circ} \mathrm{C}$ for surface tension reduction). Hence, we concluded that the RL7-11 was a better surfactant for applications in environmental remediation. It appeared that RL-STD showed a better performance than that of SDS under various $\mathrm{pH}$, salinity, and temperature conditions, but not as stable as RL7-11.

\section{Cell mass increase of ZS1 is accompanied with emulsification and consumption of crude oil}

To investigate whether ZS1 isolate was capable of utilizing crude oil for growth, which was essential for its potential application of in situ bioremediation, we performed growth analysis of ZS1 isolate in MS medium supplemented with $1 \%$ crude oil as sole carbon source (Fig. 6a). Level of total (unemulsified and emulsified) crude oil and cell biomass was determined after separation by centrifugation using gravimetric methodologies (see "Materials and methods"). Upon inoculation of ZS1 in fresh MS medium supplemented with crude oil, we found that crude oil was either adhered to sidewall of the shake-flack or floated on top of the culture (Fig. 6b, see arrow). Oil emulsion became visible $6 \mathrm{~h}$ after growth, which coincided with the cell biomass increase (Fig. 6a, b, see arrowhead). Twelve days after growth, $50 \%$ of total crude oil was consumed by the ZS1 cells, exhibiting a degradation rate of $417 \mathrm{mg} / \mathrm{l}$ days.

We subsequently investigated the consumption of hexadecane as petroleum product by ZS1 isolate. Based on the same approach, we found that $50 \%$ of total hexadecane was consumed in 5.5 days (Fig. 6c). This result indicated that ZS1 utilized refined petroleum product more effectively than crude petroleum oil.

\section{Discussion}

Biosurfactants provide a promising alternative to chemically synthesized surfactants because of their low toxicity, high biodegradability, and ecological safety (Sponza and 

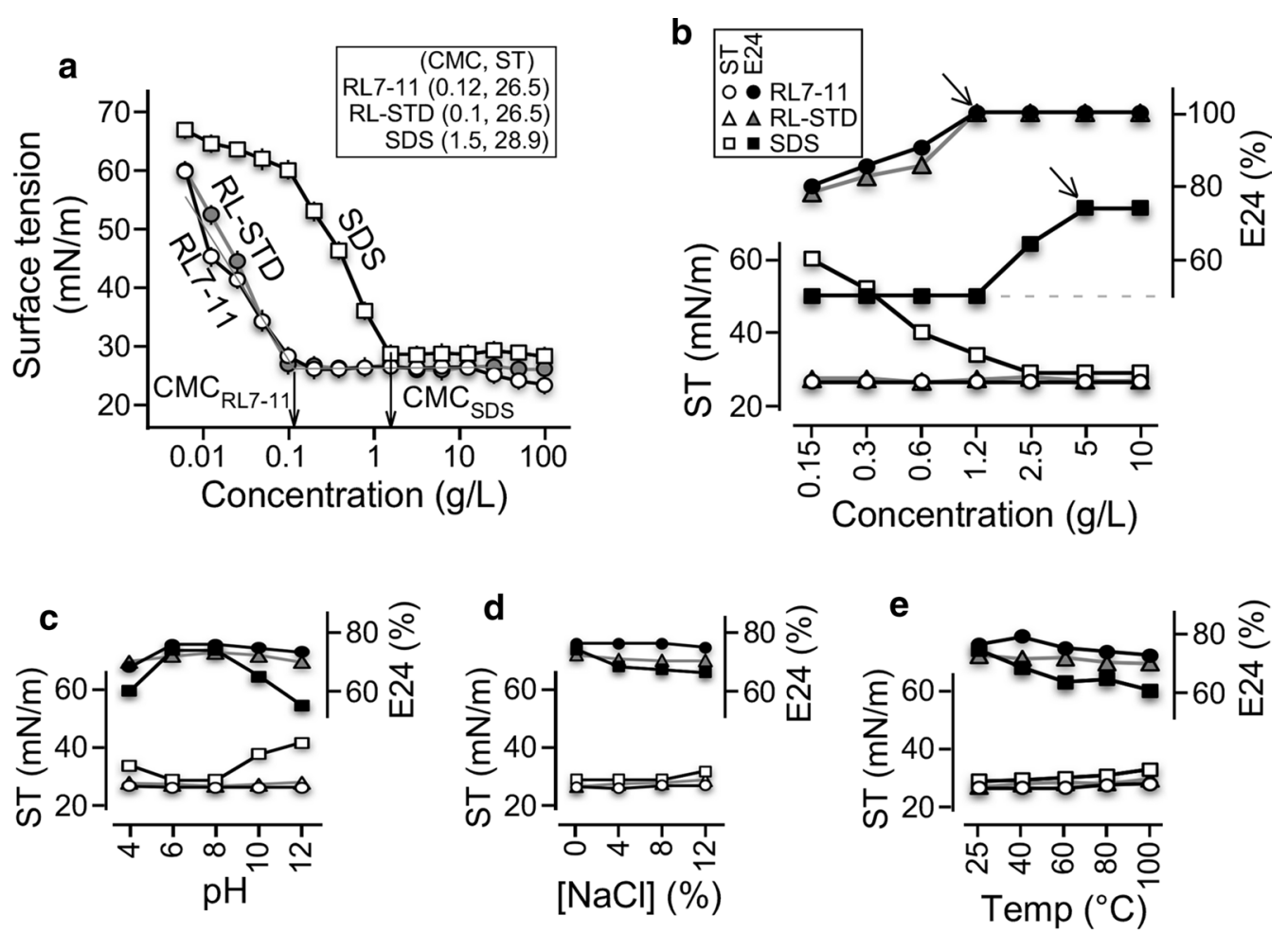

Fig. 5 Comparative analysis of surfactant activity between RL7-11, RL-STD, and SDS. a Analysis of CMC-RL7-11, CMC-RL-STD, and CMC-SDS.X- and $Y$-axis indicate surfactant concentration in $\mathrm{g} / \mathrm{l}$ and surface tension in $\mathrm{mN} / \mathrm{m}$, respectively. $\mathbf{b}$ Analysis of surface tension and emulsification capacity E24 index against crude oil. Solid and open marks indicate surface tension in $\mathrm{mN} / \mathrm{m}$ and E24 index in percent. Circle, triangle, and square indicate RL7-11, RL-STD, and SDS, respectively. Analysis of surfactant activity under various pH, salinity, and temperature conditions is shown in $\mathbf{c}$, $\mathbf{d}$ and $\mathbf{e}$, respectively. The display is identical to $\mathbf{b}$

Gök 2010). Rhamnolipids are thought to be the next-generation surfactants for its high efficacy and stability over various environmental conditions (Henkel et al. 2012; Sponza and Gök 2010). In this study, we show the isolation of a rhamnolipid-producing $P$. aeruginosa ZS1 from petroleum sludge in Zhoushan islands, China, where a national strategic petroleum reservoir is located. The ability of petroleum consumption by ZS1 makes it suitable for cleanup of petroleum pollutants in Zhoushan.

Many methods employed in screening for biosurfactant-producing microbes from petroleum pollutants in marine and terrestrial environments are often involved in firstly the separation and isolation of individual microbial colonies on plates with indicator for surfactant activities (Walter et al. 2010). Because biosurfactants may not be constitutively produced in microbes, they will either be missed during the screening or multiply the workload for screening colonies on plates under different growth conditions. To circumvent this issue, we screen biosurfactant activities in mixed cultures. Changes of microbial populations in mixed culture were monitored by a rapid real-time TFL-RFLP method.
Several environmental isolates of $P$. aeruginosa have shown to produce rhamnolipids (Abalos et al. 2001; Abdel-Mawgoud et al. 2009; Ma et al. 2016). Some isolates favor lipids instead of glucose as carbon sources (Ma et al. 2016). Additionally, ratios between carbon and nitrogen sources $(\mathrm{C} / \mathrm{N})$ affect rhamnolipid yields $(\mathrm{Ma}$ et al. 2016). In this analysis, we show that ZS1 produces rhamnolipids up to 30 and $44 \mathrm{~g} / \mathrm{l}$ at the $\mathrm{C} / \mathrm{N}$ ratio of $12: 1$ and 24:1 (respectively) in medium with glucose as sole carbon sources. Furthermore, ZS1 is capable of consuming crude oil, which make it ideal for bioremediation. These observations are consistent with the notion that nutrient preferences are isolate-dependent (Wu et al. 2008).

Up to now, the highest rhamnolipid yields are reported to be ranged from 70 to $120 \mathrm{~g} / \mathrm{l}$ by the chemically mutagenized strains DSM 7107 and DSM 7108 derived from an environmental isolate cultivating in bioreactors (Giani et al. 1997). On the other hand, the highest rhamnolipid yields from the naturally occurring isolates growing in a shaking flask are found to be up to 9.5 and $25.9 \mathrm{~g} / \mathrm{l}$ (Abalos et al. 2001; Ma et al. 2016). In this study, we show that 

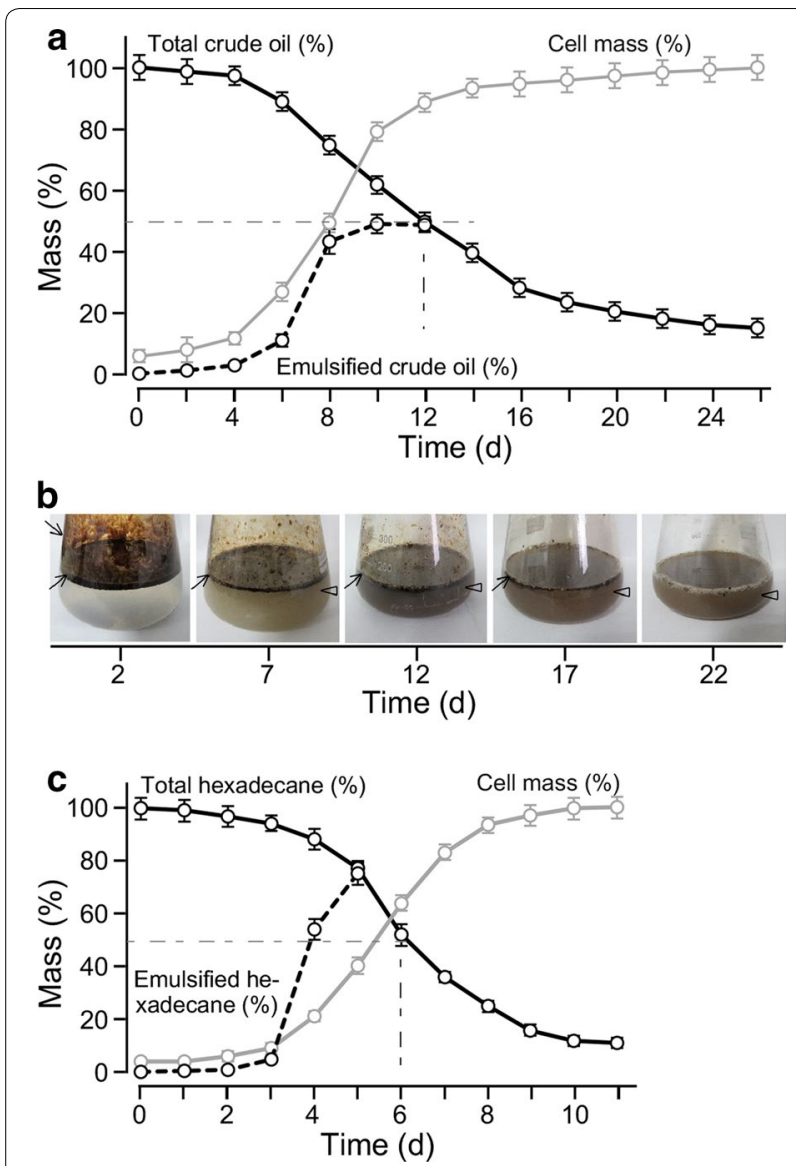

Fig. 6 ZS1 growth in medium with crude oil as sole carbon source. a Growth curve analysis of ZS1 isolate in MS medium supplemented with $1 \%$ crude oil. $X$ - and $Y$-axis indicate time (days) and percent of mass (\%) of crude oil or cell biomass. Maximum level (or 100\%) of crude oil and cell biomass are 10 and $6.5 \mathrm{~g} / \mathrm{l}$, respectively. Dash-line indicates $50 \%$ crude oil remained after growth for 12 day. b Degradation of crude oil by ZS1 isolate. Images show crude oil in shake-flask containing ZS1 culture at various time points during growth. Arrowhead and arrow indicate the unemulsified and emulsified crude oils, respectively. c Growth curve analysis of ZS1 isolate in MS medium supplemented with $1 \%$ hexadecane. The display is identical to $\mathbf{a}$

$\mathrm{ZS} 1$ isolate give rise to maximum yields of 30 and $44 \mathrm{~g} / \mathrm{l}$ after 64 and $110 \mathrm{~h}$ growth in MS medium supplemented with 2 and $4 \%$ glucose, respectively. Among the naturally occurring isolates growing in shake-flasks reported so far, the ZS1 gives the highest rhamnolipid yield. This is probably attributed to the screening in mixed population of sludge-derived microbes instead of individually isolated colonies, because microbes responsible for the strongest surfactant activities in the mixed population are readily monitored. The rapid TFL-RFLP assay on dynamics of microbial populations facilitates the identification of the surfactant-producing microbes.

Rhamnolipids are often referred as a mixture of monorhamnolipid rha- $\mathrm{C}_{10}-\mathrm{C}_{10}$ and dirhamnolipid rha-rha- $\mathrm{C}_{10}-\mathrm{C}_{10}$ (Syldatk and Wagner 1987). Many rhamnolipids produced in P. aeruginosa are found to contain multiple rhamnolipid homologues besides the most common forms (Abalos et al. 2001; Abdel-Mawgoud et al. 2009; Ma et al. 2016). In this study, we show that the ZS1 isolate produces 7 homologues of monorhamnolipids and 11 homologues of dirhamnolipids with the most dominant homologues of rha-rha- $\mathrm{C}_{10}-\mathrm{C}_{10}$ and rha$\mathrm{C}_{10}-\mathrm{C}_{10}$ (see Table 1), consistent with the notion that the common forms of rhamnolipid homologue are most dominant in rhamnolipid-producing microbes (Schenk et al. 1995; Zhang and Miller 1994). We show that the CMC of RL7-11 is a bit higher than that of RL-STD containing mainly the rha-C10-C10 and rha-rha-C10-C10 (CMC $0.12 \mathrm{~g} / \mathrm{l}$ versus $0.1 \mathrm{~g} / \mathrm{l}$ ). This could be caused by the different purities of the chemical. Notably, RL mixture containing multiple homologues appear to improve the stability under various environmental stress conditions tested (see Fig. 5).

Recently, a $P$. aeruginosa NCIM 5514 isolate has been suggested as a suitable strain for bioremediation of hydrocarbon pollutants in petrochemical industry (Varjani and Upasani 2016). In this study, we show that ZS1 isolate is capable of consuming $60 \%$ crude oil at $30{ }^{\circ} \mathrm{C}$ in 14 days. In comparison, the NCIM 5514 isolate is able to degrade $60 \%$ crude oil at $37^{\circ} \mathrm{C}$ in 60 days. The difference may be attributed to the high yield of rhamnolipids produced by ZS1 isolate. Hence, we concluded that ZS1 isolate is ideal for bioremediation of petroleum pollutants, especially in the coastal areas of Zhoushan.

In conclusion, our analyses show that $P$. aeruginosa ZS1 isolated from petroleum sludge produces biosurfactant rhamnolipids in minimal salt medium supplemented glucose, glycerol or crude oil as sole carbon source. Consumption of crude oil by ZS1 isolate is facilitated with its rhamnolipid secretion. Hence, we propose that the ZS1 isolate is suitable for bioremediation of petroleum pollutants, especially in the coast areas of Zhoushan islands.

\section{Abbreviations}

GC-MS/MS: gas chromatography coupled with tandem mass spectrometry; Rha: rhamnolipid; ST: surface tension; TFL-RFLP: terminal fluorescence labeledrestriction fragment length polymorphism; TLC: thin layer chromatography.

\section{Authors' contributions}

$\mathrm{TC}, \mathrm{JH}$, and XH carried out the biological and biophysical studies; JLiang and ZG carried out the analytic chemical studies; Jiu conceived the studies and participated in its design and coordination; and JLiu drafted the manuscript. All authors read and approved the final manuscript.

\section{Author details}

${ }^{1}$ Marine Biology, Ocean College, Zhejiang University, 1 Zheda Road, Dinghai District, Zhoushan Campus, Marine Science Building, Room 379, Zhoushan 316000, Zhejiang, China. ${ }^{2}$ Marine Functional Compounds, Ocean Research Centre of Zhoushan, Zhejiang University, Zhoushan 316021, Zhejiang, China. ${ }^{3}$ Analysis Center of Agrobiology and Environmental Sciences, Zhejiang University, Hangzhou 310058, Zhejiang, China. 


\section{Acknowledgements}

Authors would like to thank Mr. G. Zheng and J. Xiao for assistance in petroleum sludge sampling and the Analysis Center in Zhejiang University for assistance in mass spectrometry analyses. T. Cheng and J. Liang are recipients of the M.Sc. and Ph.D. scholarships (respectively) in Zhejiang University Ocean College.

\section{Competing interests}

The authors declare that they have no competing interests.

\section{Availability of data and materials}

All materials and data used in this study have deposited in publicly available repositories.

\section{Funding}

This work is funded by the Zhoushan Municipal Science and Technology Bureau (Grants 2014C51020 and 2016C51026) to J. Liu.

\section{Publisher's Note}

Springer Nature remains neutral with regard to jurisdictional claims in published maps and institutional affiliations.

Received: 23 May 2017 Accepted: 1 June 2017

Published online: 08 June 2017

\section{References}

Abalos A, Pinazo A, Infante MR, Casals M, Garcia F, Manresa A (2001) Physicochemical and antimicrobial properties of new rhamnolipids produced by Pseudomonas aeruginosa AT10 from soybean oil refinery wastes. Langmuir 17:1367-1371

Abdel-Mawgoud AM, Aboulwafa MM, Hassouna NA (2009) Characterization of rhamnolipid produced by Pseudomonas aeruginosa isolate Bs20. App Biochem Biotechnol 157(2):329-345. doi:10.1007/s12010-008-8285-1

Abdel-Mawgoud AM, Lepine F, Deziel E (2010) Rhamnolipids: diversity of structures, microbial origins and roles. Appl Microbiol Biotechnol 86(5):1323-1336

Akihiro H, Syutsubo K, Harayama S (2003) Alcanivorax which prevails in oilcontaminated seawater exhibits broad substrate specificity for alkane degradation. Environ Microbiol 5(9):746-753

Butt H-J, Graf K, Kappl M (2003) Physics and chemistry of interfaces. Wiley, New York

Chandankere R, Yao J, Choi MMF, Masakorala K, Chan Y (2013) An efficient biosurfactant-producing and crude-oil emulsifying bacterium Bacillus methylotrophicus USTBa isolated from petroleum reservoir. Biochem Eng J 74:46-53

Cooper DG, Goldenberg BG (1987) Surface-active agents from two Bacillus species. Appl Environ Microbiol 53(2):224-229

Cooper DG, Macdonald CR, Duff SJ, Kosaric N (1981) Enhanced production of surfactin from Bacillus subtilis by continuous product removal and metal cation additions. Appl Environ Microbiol 42(3):408-412

Desai JD, Banat IM (1997) Microbial production of surfactants and their commercial potential. Microbiol Mol Biol Rev 61(1):47-64

Deziel E, Lepine F, Dennie D, Boismenu D, Mamer OA, Villemur R (1999) Liquid chromatography/mass spectrometry analysis of mixtures of rhamnolipids produced by Pseudomonas aeruginosa strain 57RP grown on mannitol or naphthalene. Biochem Biophys Acta 1440(2-3):244-252

du Noüy PL (1925) An interfacial tensiometer for universal use. J Gen Physiol 7(5):625-633. doi:10.1085/jgp.7.5.625

Edward JR, Hayashi JA (1965) Structure of a rhamnolipid from Pseudomonas aeruginosa. Arch Biochem Biophys 111(2):415-421

Ernst $H$ (1997) The use of patent data for technological forecasting: the diffusion of CNC-technology in the machine tool industry. Small Bus Econ 9:361-381

Giani C, Wullbrandt D, Rothert R, Meiwes J (1997) Pseudomonas aeruginosa and its use in a process for the biotechnological preparation of L-rhamnose
Haba E, Pinazo A, Jauregui O, Espuny MJ, Infante MR, Manresa A (2003) Physicochemical characterization and antimicrobial properties of rhamnolipids produced by Pseudomonas aeruginosa 47T2 NCBIM 40044. Biotechnol Bioeng 81(3):316-322. doi:10.1002/bit.10474

Henkel M, Muller MM, Kugler JH, Lovaglio RB, Contiero J, Syldatk C, Hausmann $R$ (2012) Rhamnolipids as biosurfactants from renewable resources: concepts for next-generation rhamnolipid production. Process Biochem 47:1207-1219

Holliger C, Gaspard S, Glod G, Heijman C, Schumacher W, Schwarzenbach RP, Vazquez F (1997) Contaminated environments in the subsurface and bioremediation: organic contaminants. FEMS Microbiol Rev 20(3-4):517-523

Kanaly RA, Harayama S (2010) Advanced in the field of high-molecular-weight polycyclic aromatic hydrocarbon biodegradation by bacteria. Microb Biotechnol 3:136-164

Kvenvolden KA, Cooper CK (2003) Natural seepage of crude oil into the marine environment. Geo-Marine Lett 23(3-4):140-146

Lang S, Wullbrandt D (1999) Rhamnose lipids-biosynthesis, microbial production and application potential. Appl Microbiol Biotechnol 51(1):22-32

Larkin MA, Blackshields G, Brown NP, Chenna R, McGettigan PA, McWilliam H, Valentin F, Wallace IM, Wilm A, Lopez R, Thompson JD, Gibson TJ, Higgins DG (2007) Clustal W and clustal X version 2.0. Bioinformatics 23(21):29472948. doi:10.1093/bioinformatics/btm404

Ma KY, Sun MY, Dong W, He CQ, Chen FL, Ma YL (2016) Effects of nutrition optimization strategy on rhamnolipid production in a Pseudomonas aeruginosa strain DN1 for bioremediation of crude oil. Biocatal Agric Biotechnol 6:144-151

Marchant R, Banat IM (2014) Protocol for measuring biosurfactant production in microbial cultures. Humana Press, New York

Mata-Sandoval JC, Karns J, Torrents A (1999) High-performance liquid chromatography method for the characterization of rhamnolipids mixtures produced by Pseudomonas aeruginosa UG2 on corn oil. J Chromatogr A 864:211-220

Meyer P (1994) Bi-logistic growth. Technol Forecast Soc Change 47:89-102

Moreno C, Romero J, Espejo RT (2002) Polymorphism in repeated $16 \mathrm{~S}$ rRNA genes is a common property of type strains and environmental isolates of the genus Vibrio. Microbiology 148(Pt 4):1233-1239. doi:10.1099/00221287-148-4-1233

Morikawa M, Hirata Y, Imanaka T (2000) A study on the structure-function relationship of lipopeptide biosurfactants. Biochem Biophys Acta 1488(3):211-218

Muller MM, Kugler JH, Henkel M, Gerlitzki M, Hormann B, Pohnlein M, Syldatk C, Hausmann R (2012) Rhamnolipids - next generation surfactants? J Biotechnol 162(4):366-380. doi:10.1016/j.jbiotec.2012.05.022

Murphy M, Alkhalidi M, Crocker J, Lee S, Oregan P, Acott P (2005) Two formulations of the industrial surfactant, toximul, differentially reduce mouse weight gain and hepatic glycogen in vivo during early development: effects of exposure to influenza B Virus. Chemosphere 59(2):235-246

Naether DJ, Slawtschew S, Stasik S, Engel M, Olzog M, Wick LY, Timmis KN, Heipieper HJ (2013) Adaptation of the hydrocarbonoclastic bacterium Alcanivorax borkumensis SK2 to alkanes and toxic organic compounds: a physiological and transcriptomic approach. Appl Environ Microbiol 79(14):4282-4293 doi:10.1128/AEM.00694-13

Ochsner UA, Fiechter A, Reiser J (1994a) Isolation, characterization, and expression in Escherichia coli of the Pseudomonas aeruginosa rhIAB genes encoding a rhamnosyltransferase involved in rhamnolipid biosurfactant synthesis. J Biol Chem 269(31):19787-19795

Ochsner UA, Koch AK, Fiechter A, Reiser J (1994b) Isolation and characterization of a regulatory gene affecting rhamnolipid biosurfactant synthesis in Pseudomonas aeruginosa. J Bacteriol 176(7):2044-2054

Rahim R, Ochsner UA, Olvera C, Graninger M, Messner P, Lam JS, Soberon-Chavez $\mathrm{G}$ (2001) Cloning and functional characterization of the Pseudomonas aeruginosa $\mathrm{rhlC}$ gene that encodes rhamnosyltransferase 2, an enzyme responsible for di-rhamnolipid biosynthesis. Mol Microbiol 40(3):708-718

Rehm BHA, Kruger N, Steinbuchel A (1998) A new metabolic link between fatty acid de novo synthesis and polyhydroxyalkanoic acid synthesis - the phaG gene from Pseudomonas putida KT2440 encodes a 3-hydroxyacyl-acyl carrier protein coenzyme A transferase. J Biol Chem 273:24044-24051 
Santa Anna LM, Sebastian GV, Menezes EP, Alves TLM, Santos AS, Pereira N Jr, Freire DMG (2002) Production of biosurfactants from Pseudomonas aeruginosa PA1 isolated in oil environments. Braz J Chem Eng 19(2):159-166 Schenk T, Schuphan I, Schmidt B (1995) High-performance liquid chromatographic determination of the rhamnolipids produced by Pseudomonas aeruginosa. J Chromatogr A 693(1):7-13

Shoham Y, Rosenberg M, Rosenberg E (1983) Bacterial degradation of emulsan. Appl Environ Microbiol 46(3):573-579

Soberón-Chávez G, Aguirre-Ramírez M, Sánchez R (2005) The Pseudomonas aeruginosa RhlA enzyme is involved in rhamnolipid and polyhydroxyalkanoate production. J Ind Microbiol Biotechnol 32(11-12):675-677

Sponza DT, Gök O (2010) Effect of rhamnolipid on the aerobic removal of polyaromatic hydrocarbons (PAHs) and COD components from petrochemical wastewater. Bioresour Technol 101(3):914-924

Syldatk C, Wagner F (1987) Production of biosurfactants, vol 5. Marcel Dekker, New York

Tamura K, Stecher G, Peterson D, Filipski A, Kumar S (2013) MEGA6: molecular evolutionary genetics analysis version 6.0. Mol Biol Evol 30(12):27252729. doi:10.1093/molbev/mst197

Varjani SJ, Upasani VN (2016) Biodegradation of petroleum hydrocarbons by oleophilic strain of Pseudomonas aeruginosa NCIM 5514. Bioresour Technol 222:195-201. doi:10.1016/j.biortech.2016.10.006

Walter V, Syldatk C, Hausmann R (2010) Screening concepts for the isolation of biosurfactant producing microorganisms. Adv Exp Med Biol 672:1-13
Wu JY, Yeh KL, Lu WB, Lin CL, Chang JS (2008) Rhamnolipid production with indigenous Pseudomonas aeruginosa EM1 isolated from oilcontaminated site. Bioresour Technol 99(5):1157-1164. doi:10.1016/j. biortech.2007.02.026

Yakimov MM, Timmis KN, Golyshin PN (2007) Obligate oil-degrading marine bacteria. Curr Opin Biotechnol 18(3):257-266. doi:10.1016/j. copbio.2007.04.006

Zajic E, Supplison B (1972) Emulsification and degradation of "Bunker C" fuel oil by microorganisms. Biotechnol Bioeng 14:331-334

Zhang Y, Miller RM (1992) Enhanced octadecane dispersion and biodegradation by a Pseudomonas rhamnolipid surfactant (biosurfactant). Appl Environ Microbiol 58(10):3276-3282

Zhang Y, Miller RM (1994) Effect of a Pseudomonas rhamnolipid biosurfactant on cell hydrophobicity and biodegradation of octadecane. Appl Environ Microbiol 60(6):2101-2106

Zhang L, Veres-Schalnat TA, Somogyi A, Pemberton JE, Maier RM (2012) Fatty acid cosubstrates provide beta-oxidation precursors for rhamnolipid biosynthesis in Pseudomonas aeruginosa, as evidenced by isotope tracing and gene expression assays. Appl Environ Microbiol 78(24):8611-8622. doi:10.1128/AEM.02111-12

\section{Submit your manuscript to a SpringerOpen ${ }^{\circ}$ journal and benefit from:}

- Convenient online submission

Rigorous peer review

- Immediate publication on acceptance

- Open access: articles freely available online

- High visibility within the field

- Retaining the copyright to your article

Submit your next manuscript at springeropen.com 